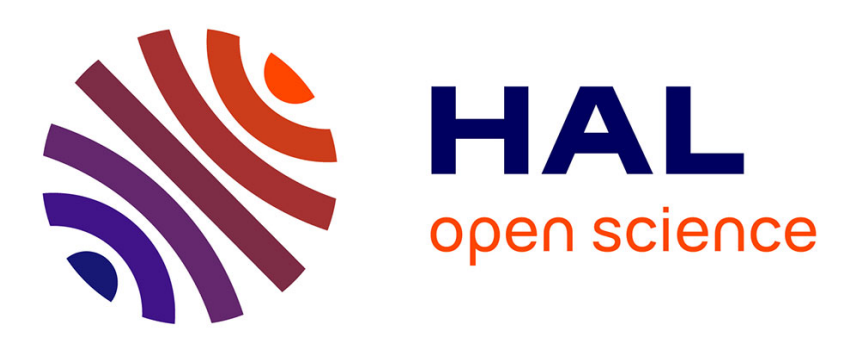

\title{
Supramolecular rectangles through directional chalcogen bonding
}

\author{
Arun Dhaka, Olivier Jeannin, Emmanuel Aubert, Enrique Espinosa, Marc \\ Fourmigue
}

\section{- To cite this version:}

Arun Dhaka, Olivier Jeannin, Emmanuel Aubert, Enrique Espinosa, Marc Fourmigue. Supramolecular rectangles through directional chalcogen bonding. Chemical Communications, 2021, 57 (37), pp.45604563. 10.1039/d1cc00789k . hal-03217084

\section{HAL Id: hal-03217084 \\ https://hal.science/hal-03217084}

Submitted on 18 Jun 2021

HAL is a multi-disciplinary open access archive for the deposit and dissemination of scientific research documents, whether they are published or not. The documents may come from teaching and research institutions in France or abroad, or from public or private research centers.
L'archive ouverte pluridisciplinaire HAL, est destinée au dépôt et à la diffusion de documents scientifiques de niveau recherche, publiés ou non, émanant des établissements d'enseignement et de recherche français ou étrangers, des laboratoires publics ou privés. 


\section{COMMUNICATION}

\section{Supramolecular rectangles through directional chalcogen bonding $\dagger$}

Received 00th January 20xx,

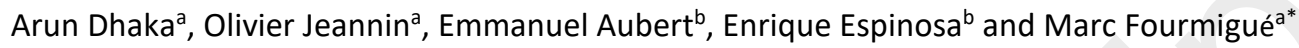

Accepted 00th January 20xx

DOI: $10.1039 / \times 0 \times x 00000 x$

Supramolecular rectangles are built from the $2+2$ chalcogen bonding-based (ChB) association of 1,8-bis(telluromethylethynyl)anthracene (BTMEA) and ditopic Lewis bases such as 4,4'-bipyridylethane and analogs, demonstrating the strength and directionnality of the ChB interaction in such alkynyl-telluroalkyl derivatives.

The field of crystal engineering, originally evolving in the frame of hydrogen bonding, ${ }^{1}$ concerns the control of solid-state molecular organization with the understanding of intermolecular interactions to eventually achieve desired functional outcome. ${ }^{2}$ Coordination complexes also offer a simple way to build desired solid-state structures through metal coordination with their predictable geometrical fate 3 but over the time this focus rapidly shifted toward supramolecular synthesis ${ }^{4,5}$ involving non-covalent interactions. In this context, halogen bonding $(X B)^{6,7}$ has emerged in the category of sigma-hole interactions as an effective tool in supramolecular synthesis of 1D, 2D or 3D solid-state structures. ${ }^{8-10}$ Similarly, chalcogen bonding $(\mathrm{ChB})$ has been defined as an attractive interaction between an electron depleted area of a chalcogen atom and a Lewis-base. ${ }^{11-14}$ At variance with monovalent halogens, a divalent chalcogen atom bears two sigma-holes roughly in the prolongation of each covalent bond that strongly limits the predictability of chalcogen bonding interactions. In this context, use of $\mathrm{ChB}$ donors toward supramolecular architectures still remains very limited. Earlier examples include alkyltelluroalkynyl derivatives reported by Gleiter, with in one instance a supramolecular nanotube supported by Te••-Te interactions. ${ }^{15-17}$ Some notable examples of amphoteric $\mathrm{ChB}$ donors/acceptors include $\mathrm{S}(\mathrm{CN})_{2},{ }^{18} \mathrm{Se}(\mathrm{CN})_{2,}{ }^{19} 1,2,5-$ chalcogenadiazoles, ${ }^{20,21}$ benzo-1,3-chalcogenazo-les ${ }^{22}$ or benzo-1,2chalcogenazole $\mathrm{N}$-oxides ${ }^{23,24}$ that self-associate into discrete or extended solid-state structures through ChB (Scheme 1a). More rarely, chalcogen bond donors have been employed into cocrystals

a. Univ Rennes, CNRS, ISCR (Institut des Sciences Chimiques de Rennes) UMR 6226, 35042 Rennes, France. E-mail: marc.fourmigue@univ-rennes1.fr

b. Université de Lorraine, CNRS, CRM2, F-54000 Nancy, France

† Electronic Supplementary Information (ESI) available: Experimental details on syntheses, crystal growth, crystallography and DFT calculations. CCDC 20594242059427. For ESI and crystallographic data in CIF or other electronic format see DOI: $10.1039 / x 0 x \times 00000 x$ (a) ChB self-association

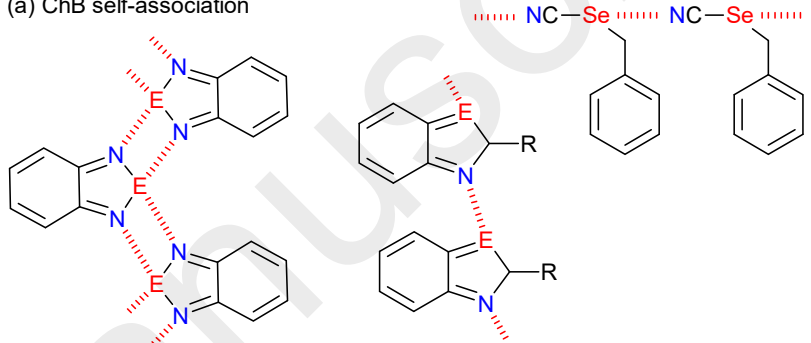

(b) ChB co-crystals

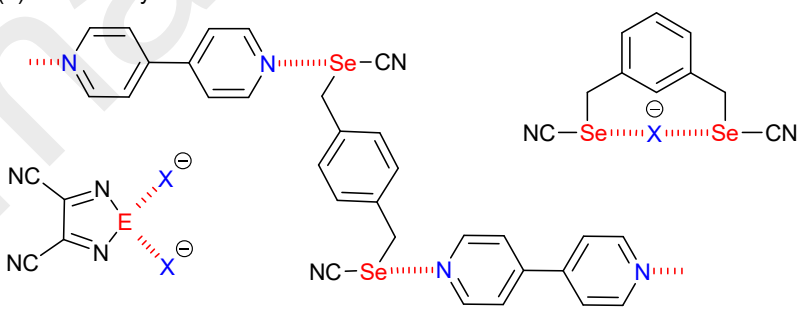

(c) $\mathrm{XB}$ rectangles

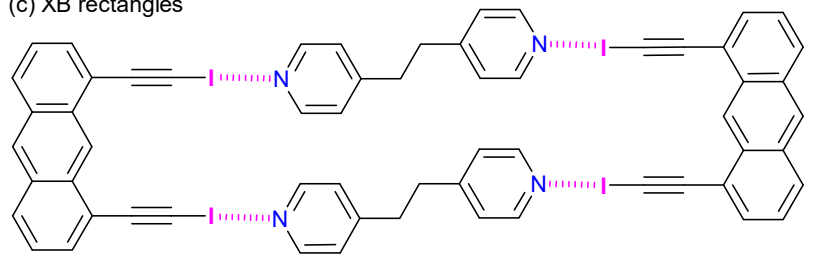

Scheme 1 Examples of ChB or XB supramolecular structures. E and $\mathrm{X}$ stand for $\mathrm{Se} / \mathrm{Te}$ and halide anion respectively.

with neutral Lewis bases or with halide anions (Scheme 1b). ${ }^{25,26}$

The design and construction of discrete supramolecular architectures through intermolecular interactions require installation of highly directional and strongly interacting sites at specific positions on both donor and acceptor molecules. For instance, XB triangular motifs, formerly observed in the hexachlorobenzene and hexabromobenzene crystal structures where halogen atoms bear at the time anchoring electrophilic and nucleophilic sites leading to $180^{\circ} / 120^{\circ}$ geometries, ${ }^{27}$ were then engineered by directing self-complementary donor and acceptor sites at an angle of $60^{\circ}$ along the sides of an equilateral triangle using triiodoimidazolium $^{28}$ or iodoethynylpyridine ${ }^{29}$ XB donors. Similarly, 
based on ChB, benzo-2,1,3-chalcogenodiazole-based cavitands were shown to form a homo-molecular dimeric capsule through multiple Chø•N interactions. ${ }^{30}$ The targeted formation of discrete, but heteromolecular halogen-bonded assemblies is illustrated for example by rectangular motifs formed upon co-crystallization of complementary ditopic XB donors such as 1,8diiodoethynylanthracene and ditopic XB acceptors such as 1,2-bis(4pyridyl)ethane (bpe) (Scheme 1c). ${ }^{31}$ The reverse situation is also reported, from a U-shaped anthracene-based ditopic Lewis base with linear ditopic halogen bond donors. ${ }^{32}$ To the best of our knowledge, chalcogen-bonded, discrete, heteromolecular supramolecular architectures have not been reported so far and still remain challenging. The only examples of such heteromolecular species involve solvates of 2,1,3-telluradiazole dimers with DMSO or pyridine as ChB acceptors. ${ }^{33,34}$ This fact can be attributed to the weaker linearity/predictability of chalcogen bonding compared to that of halogen bonding and more difficult integration of $\mathrm{ChB}$ donor sites in a molecule with a controlled orientation.

One strategy to circumvent the predictability of $\mathrm{ChB}$ in crystal engineering relies on a disymmetrisation of the chalcogen atom, with only one strongly electron-withdrawing substituent. For example, organic selenocyanates such as bis(selenocyanatomethyl)-benzene derivatives were shown to form chalcogen bonded 1D chains with 4,4'-bipyridine through short and directional Se $\bullet \bullet N_{\mathrm{Py}}$ contacts (Scheme 1b). ${ }^{35,36}$ Also, activation of a strong sigma-hole on chalcogen atom has been recently demonstrated in alkylseleno/ alkyltelluroacetylenes as rigid ditopic ChB donors and a remarkable control of directionality to engineer $1 D$ chalcogen-bonded chain motifs engaging ditopic Lewis-bases. ${ }^{37}$ We envisioned this alkynyl approach to be a potential route to design and engineer supramolecular heteromolecular macrocycles under $\mathrm{ChB}$ control. Inspired from the work on 1,8-diiodoethynylanthracene XB donor (Scheme 1c), ${ }^{31}$ we considered replacing both iodine atoms with telluroalkyl moieties, anticipating that the strong activation of a sigma-hole on the tellurium atom in the prolongation of the $(\mathrm{C} \equiv \mathrm{C})-\mathrm{Te}$ bond could similarly favor supramolecular assembly into discrete rectangles upon co-crystallization with a ditopic Lewis-base, as shown in Scheme 2.

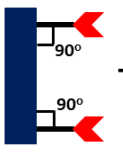

Donor
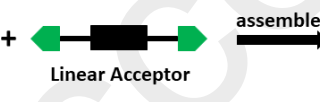

Linear Accepto

Scheme 2 Design principle and structural requirements in donor and acceptor molecules to build a supramolecular rectangle.

Herein, we report the synthesis of 1,8-bis(telluromethylethynyl)anthracene (BTMEA), a new U-shaped ditopic ChB donor and its cocrystallization with various linear ditopic Lewis bases, resulting into the sought-after heteromolecular rectangles. Calculations of electrostatic potential surface of BTMEA (Fig. 1) revealed the presence of a deep electron depletion area in the prolongation of the $(\mathrm{C} \equiv \mathrm{C})-\mathrm{Te}$ bonds with $\mathrm{V}_{\max }$ values of $+38.8 \mathrm{kcal} \mathrm{mol}^{-1}$, comparable to those found in similar iodoalkynyl derivatives. ${ }^{37}$ This feature already

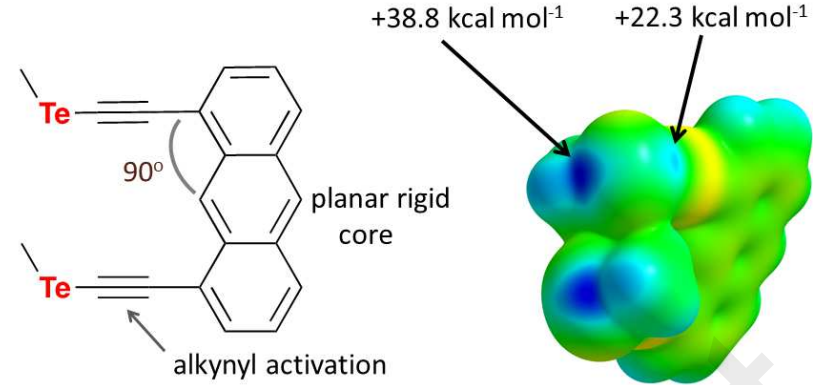

Fig. 1 Electrostatic potential map (plotted on the $0.002 \mathrm{e} / \mathrm{bohr}^{3}$ isosurface of the electronic density) of BTMEA in optimized geometry showing the two $\sigma$-holes in the prolongation of the $(\mathrm{C} \equiv \mathrm{C})-\mathrm{Te}$ and $\mathrm{Me}-\mathrm{Te}$ bonds.

establishes the ability and the linear disposition of the $\sigma$-hole in the chalcogen bond donor of BTMEA, as anticipated (Scheme 2). Note also the second, weaker $\sigma$-hole along the Me-Te bond which will contribute to the overall structural organization (See ESI for details).

Synthesis of BTMEA ChB donor starts with 1,8dibromoanthracene $\mathbf{1}$ to first obtain compound $\mathbf{2}$ through Sonogashira coupling followed by reaction of the corresponding silver salt $\mathbf{3}$ (caution, alkynyl silver salts might be explosive) with methyltelluronium bromide $\mathrm{MeTe}-\mathrm{Br}$ (Scheme 3). 1,8-Dibromoanthracene 1 was prepared following reported procedures from 1,8dichloroanthraquinone (see ESI).

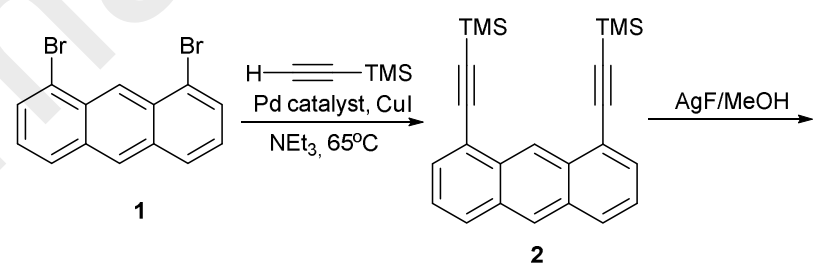<smiles>[Ge]C#Cc1cccc2cc3cccc(C#C[Ge])c3cc12</smiles>
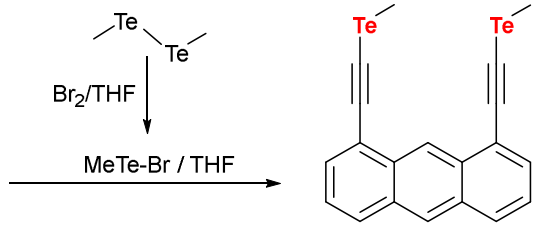

BTMEA
Scheme 3 Synthetic route to BTMEA.

The formation of heteromolecular supramolecular boxes was investigated through co-crystallization experiments of this new $\mathrm{U}$ shaped ChB donor and several linear ditopic Lewis-bases (Scheme 4).

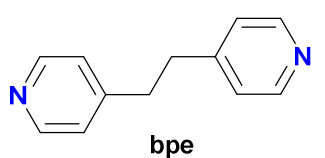

bpe<smiles>c1cc(N=Nc2ccncc2)ccn1</smiles>

azopy

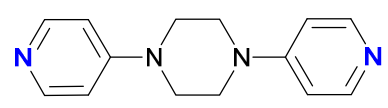

bpy-pip

bpen

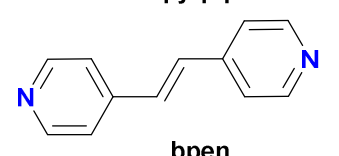

Scheme 4 Ditopic linear ChB acceptors employed in this study. 
Co-crystallization with bpe resulted indeed into the formation of the predicted rectangular motif, held together by four short Te $\bullet \bullet N$ ChB contacts in the range $2.85-2.94 \AA$, which correspond to a reduction ratio relative to the sum of van der Waals radii $[2.06(\mathrm{Te})+1.55(\mathrm{~N})=$ $3.61 \AA ̊]$ ] down to 0.79 (Fig. 2). The ChB directionality in this motif is manifested by the presence of highly linear $\mathrm{Te} \bullet \bullet \mathrm{N}$ contacts with $(\mathrm{C} \equiv) \mathrm{C}-\mathrm{Te} \bullet \bullet \mathrm{N}$ angles in the range $172-175^{\circ}$ (Fig. 2). These structural features demonstrate thus the excellent efficiency of the alkynyl substitution for the elaboration of $\mathrm{ChB}$ supramolecular architectures.

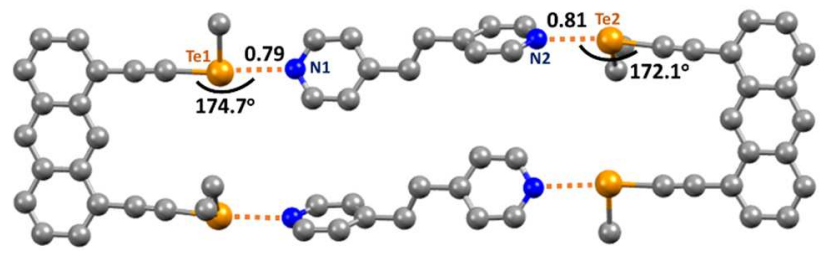

Fig. 2 Detail of the rectangular motif in the 2:2 co-crystal BTMEA•bpe. Hydrogens are omitted for clarity. The methyl group on Te2 is disordered over two positions with 65:35

To further prove the efficiency of this approach, we considered employing the bipyridylpiperazine derivative (bpy-pip) which is slightly longer and has the advantage of a stronger Lewis-base character, comparable to that of dimethylaminopyridine derivatives. ${ }^{37}$ In this case, we similarly observed the formation of 2:2 complex with two independent donor and acceptor molecules in the asymmetric unit, leading to two crystallographically independent rectangles with equally short Te••N contacts (Fig. 3 ).
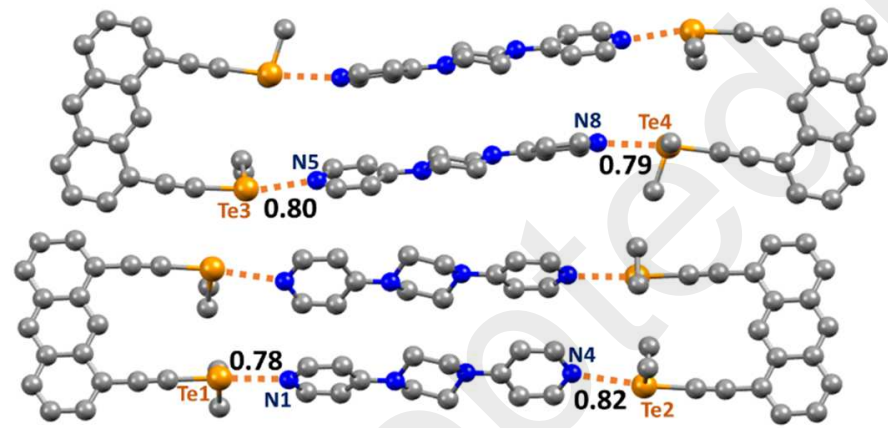

Fig. 3 The two rectangular motifs found in the 2:2 co-crystal BTMEA•bpy-pip. Hydrogens are omitted for clarity. The methyl groups are disordered over two positions with 45: 55 distribution on Te1, 49:51 on Te2, 53:47 on Te3, and 23:77 on Te4.

An analogous ditopic Lewis base, namely 4,4'-azopyridine (azopy), a chemo- and photo-responsive candidate, ${ }^{36}$ has been extensively used in metal organic frameworks, supramolecular chemistry, and crystal engineering with $\mathrm{XB}, 37,38$ but to our surprise this molecule has never been used as $\mathrm{ChB}$ acceptor. This further motivated us to use azopy in our co-crystallization experiments and consequently we observed again a 2:2 complex with BTMEA (Fig. 4), isostructural with the BTMEA•bpe co-crystal, and characterized by

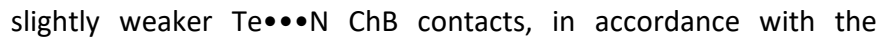
decreased Lewis base character of azopy. Note that the analogous 1,8-diiodoethynylanthracene XB donor (Scheme 1c) does not form a rectangular motif with azopy but instead favours a 1:2 (donor:acceptor) complex giving rise to a trimeric structure. ${ }^{31}$

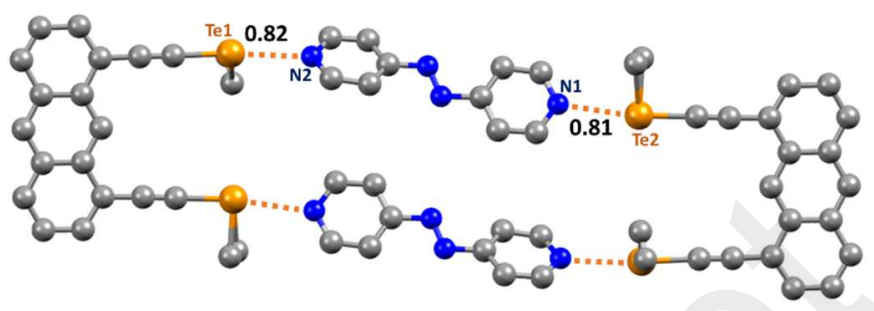

Fig. 4 X-ray crystal structure of 2:2 co-crystal between BTMEA and azopy. Hydrogens are omitted for clarity. The methyl groups on tellurium atoms are disordered over two positions with 27:73 distribution on Te1, 65:35 on Te2.

Actually, a similar 1:2 trimeric structure was also isolated in our cocrystallization experiments between BMTEA and the closely related bpen Lewis base (Fig. 5). Our attempts to favour the rectangle formation by working with a default of bpen was unsuccessful. Such bpen derivatives, when organized into a face-to-face arrangement at relatively short distances $(<4.2 \AA)$ are prone to exhibit a [2+2] cycloaddition under UV irradiation. ${ }^{41}$ Templates acting as hydrogen bond ${ }^{42}$ or halogen ${ }^{43}$ bond donors have been reported to organize bpen molecules in this expected face-to face organization. The templating effect of the BTMEA molecule, even if restricted here to the open box, might also favour such a topochemical reaction. Accordingly, we irradiated our crystals within a UV reactor equipped with a Hg lamp (254 nm) but did not observe any change. This behaviour might find its origin either in the somehow large distances between the ethylenic moieties of the bpen molecules (3.862 and $4.363 \AA$ ) in the (BTMEA)(bpen) 2 co-crystal, or the light absorption properties of the crystals.

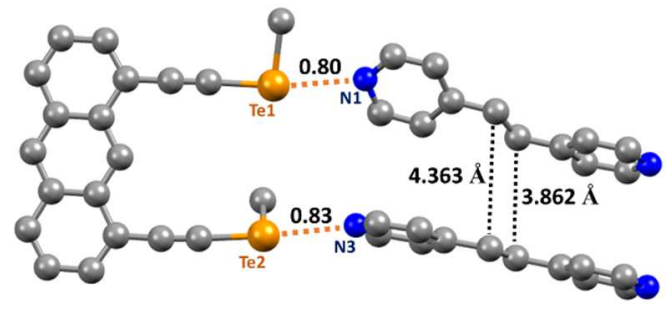

Fig. 5 X-ray crystal structure of 1:2 co-crystal between BTMEA and bpen. Hydrogens are omitted for clarity.

The four ChB structures reported here also offer the opportunity

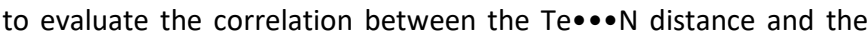
Lewis-base character of the ChB acceptors. The latter has been evaluated from the extremum value $V_{s, m i n}$ of the ESP on the nitrogen atom of the four bipyridine derivatives (see Figs S1-S4 in ESI). As shown in Table 1, the ranking of $V_{\text {min }}$ magnitudes parallels that of the shortest Te $\bullet \bullet N$ distance (in bold in Table 1) observed for each acceptor, indicating that stronger electrostatic interactions correspond indeed to the most electron-rich pyridines along the series bipy-pip $>$ bpe $>$ bpen $>$ azopy. 
Table 1 Evolution of Te $\bullet \bullet N$ distances with $\mathrm{V}_{\mathrm{s}, \min }$ on the $\mathrm{N}$ atom.

\begin{tabular}{lccc}
\hline Compound & $\begin{array}{c}\mathrm{V}_{\mathrm{s}, \min } \\
(\mathrm{kcal} / \mathrm{mol})\end{array}$ & $\begin{array}{c}\mathrm{Te} \bullet \bullet \mathrm{N} \\
(\AA)\end{array}$ & $\begin{array}{c}<\mathrm{Te} \bullet \bullet N> \\
(\AA)\end{array}$ \\
\hline bpy-pip & -45.61 & $\mathbf{2 . 8 2 4}, 2.885$, & 2.900 \\
& & $2.914,2.976$ & \\
bpe & -41.92 & $\mathbf{2 . 8 5 4 , 2 . 9 4 3}$ & 2.899 \\
bpen & -40.90 & $\mathbf{2 . 9 1 0 , 3 . 0 0 3}$ & 2.957 \\
azopy & -38.34 & $\mathbf{2 . 9 2 7}, 2.961$ & 2.944 \\
\hline
\end{tabular}

In conclusion, we have demonstrated here that the combination of tellurium activation through alkynyl substitution, with a proper orientation of the two alkynyltelluromethyl moieties on the anthracene core, provides an efficient template for the successful construction of robust molecular rectangles, stabilized by very short and highly linear $(\mathrm{C} \equiv) \mathrm{C}-\mathrm{Te} \bullet \bullet \mathrm{N}$ chalcogen bonding interactions. These results open perspectives toward the elaboration of higher complexity polygons through a control of the relative orientation and number of the telluroalkynyl linkers. Also, the possibility for threecomponent structures involving a third molecular entity stabilized within such a cage is also a future attractive target, made possible by the robustness of these rectangular motifs.

This work has been supported by ANR (France) under contracts numbers ANR-17-CE07-0025-01 (Nancy) and ANR-17-CE07-0025-02 (Rennes). The EXPLOR mesocentre is thanked for computing facilities (Project 2019CPMXX0984).

\section{Notes and references}

1 C. B. Aakeröy and K. R. Seddon, Chem. Soc. Rev., 1993, 22, 397407.

2 G. R. Desiraju, J. Am. Chem. Soc., 2013, 135, 9952-9967.

3 T. Kawano, J. Kuwana, C.-X. Du and I. Ueda, Inorg. Chem., 2002, 41, 4078-4080.

4 J. Lehn, Science, 1993, 260, 1762-1763.

5 G. R. Desiraju, Angew. Chem. Int. Ed. Engl., 1995, 34, 23112327.

6 G. R. Desiraju, P. S. Ho, L. Kloo, A. C. Legon, R. Marquardt, P. Metrangolo, P. Politzer, G. Resnati and K. Rissanen, Pure Appl. Chem., 2013, 85, 1711-1713.

7 G. Cavallo, P. Metrangolo, R. Milani, T. Pilati, A. Priimagi, G. Resnati and G. Terraneo, Chem. Rev., 2016, 116, 2478-2601.

8 P. Metrangolo and G. Resnati, Chem. Eur. J., 2001, 7, 25112519.

9 M. Fourmigué, Curr. Op. Solid State Mater. Sc., 2009, 13, 36-45.

10 L. C. Gilday, S. W. Robinson, T. A. Barendt, M. J. Langton, B. R. Mullaney and P. D. Beer, Chem. Rev., 2015, 115, 7118-7195.

11 C. B. Aakeroy, D. L. Bryce, G. R. Desiraju, A. Frontera, A. C. Legon, F. Nicotra, K. Rissanen, S. Scheiner, G. Terraneo, P. Metrangolo and G. Resnati, Pure Appl. Chem., 2019, 91, 18891892.

12 P. Scilabra, G. Terraneo and G. Resnati, Acc. Chem. Res., 2019, 52, 1313-1324.

13 L. Vogel, P. Wonner and S. M. Huber, Angew. Chem. Int. Ed., 2019, 58, 1880-1891.

14 M. Fourmigué and A. Dhaka, Coord. Chem. Rev., 2020, 403 213084
15 D. B. Werz, R. Gleiter, F. Rominger, J. Am. Chem. Soc., 2002, 124, 10638-10639.

16 D. B. Werz, R. Gleiter, J. Org. Chem., 2003, 68, 9400-9405.

17 R. Gleiter, G. Haberhauer, D.B. Werz, F. Rominger, C. Bleiholder, Chem. Rev., 2018, 118, 2010-2041.

18 E. Alikhani, F. Fuster, B. Madebene and S. J. Grabowski, Phys. Chem. Chem. Phys., 2014, 16, 2430-2442.

19 C. J. Burchell, P. Kilian, A. M. Z. Slawin, J. D. Woollins, K. Tersago, C. Van Alsenoy and F. Blockhuys, Inorg. Chem., 2006, 45, 710716.

20 G. E. Garrett, G. L. Gibson, R. N. Straus, D. S. Seferos and M. S. Taylor, J. Am. Chem. Soc., 2015, 137, 4126-4133.

21 A. F. Cozzolino, I. Vargas-Baca, S. Mansour and A. H. Mahmoudkhani, J. Am. Chem. Soc., 2005, 127, 3184-3190.

22 A. Kremer, A. Fermi, N. Biot, J. Wouters and D. Bonifazi, Chem. Eur. J., 2016, 22, 5665-5675.

23 P. C. Ho, P. Szydlowski, J. Sinclair, P. J. W. Elder, J. Kübel, C. Gendy, L. M. Lee, H. Jenkins, J. F. Britten, D. R. Morim and I. Vargas-Baca, Nature Comm., 2016, 7, 1-10.

24 P. C. Ho, J. Ra, J. F. Britten, A. L. Braga and I. Vargas-Baca, Dalton Trans., 2017, 10.

25 N. A. Semenov, N. A. Pushkarevsky, J. Beckmann, P. Finke, E. Lork, R. Mews, I. Y. Bagryanskaya, Y. V. Gatilov, S. N. Konchenko, V. G. Vasiliev and A. V. Zibarev, Eur. J. Inorg. Chem., 2012, 36933703.

26 A. M. S. Riel, H.-T. Huynh, O. Jeannin, O. Berryman and M. Fourmigué, Cryst. Growth Des., 2019, 19, 1418-1425.

27 M. E. Brezgunova, E. Aubert, S. Dahaoui, P. Fertey, S. Lebegue, C. Jelsch, J. G. Angyan and E. Espinosa, Cryst. Growth Des., 2012, 12, 5373-5386

28 T. Mukai and K. Nishikawa, X-ray Struct. Anal. Online, 2013, 29, 13-14.

29 P. M. J. Szell, A. Siiskonen, L. Catalano, G. Cavallo, G. Terraneo, A. Priimagi, D. L. Bryce and P. Metrangolo, New J. Chem., 2018, 42, 10467-10471.

30 L.-J. Riwar, N. Trapp, K. Root, R. Zenobi and F. Diederich, Angew. Chem. Int. Ed., 2018, 57, 17259-17264.

31 T. K. Wijethunga, M. Đaković, J. Desper and C. B. Aakeröy, Acto Cryst B, 2017, 73, 163-167.

32 E. Nieland, T. Topornicki, T. Kunde and B. M. Schmidt, Chem. Comm., 2019, 55, 8768-8771.

33 A. F. Cozzolino, J. F. Britten and I. Vargas-Baca, Cryst. Growth Des., 2006, 6, 181-186.

34 A. F. Cozzolino, P. S. Whitfield, and I. Vargas-Baca, J. Am. Chem. Soc., 2010, 132, 17265-17270.

35 H.-T. Huynh, O. Jeannin and M. Fourmigué, Chem. Commun., 2017, 53, 8467-8469.

36 O. Jeannin, H.-T. Huynh, A. M. S. Riel and M. Fourmigué, New J. Chem., 2018, 42, 10502-10509.

37 A. Dhaka, O. Jeannin, I.-R. Jeon, E. Aubert, E. Espinosa and M. Fourmigué, Angew. Chem. Int. Ed., 2020, 132, 23789-23793.

38 H. M. D. Bandara and S. C. Burdette, Chem. Soc. Rev., 2012, 41 1809-1825.

39 D. Fox, P. Metrangolo, D. Pasini, T. Pilati, G. Resnati and G. Terraneo, CrystEngComm, 2008, 10, 1132.

40 P. Ravat, S. SeethaLekshmi, S. N. Biswas, P. Nandy and S. Varughese, Cryst. Growth Des., 2015, 15, 2389-2401.

41 G. M. J. Schmidt, Pure Appl. Chem., 1971, 27, 647-678.

42 S. Ghorai, J. C. Sumrak, K. M. Hutchins, D. Bucar, A. V. Tivanski and L. R. MacGillivray, Chem. Sci., 2013, 4, 4303-4308.

43 T. Caronna, R. Liantonio, T. A. Logothetis, P. Metrangolo, T. Pilati and G. Resnati, J. Am. Chem. Soc., 2004, 126, 4500-4501. 